\title{
Pilot-point optimization of mining boundaries for lateritic metal deposits: finding the trade-off between dilution and ore loss
}

\author{
Yasin Dagasan - Philippe Renard \\ Julien Straubhaar • Oktay Erten . \\ Erkan Topal
}

Received: date / Accepted: date

\begin{abstract}
Geological contacts in lateritic metal deposits (footwall topographies) often delineate the orebody boundaries. Spatial variations seen in such contacts are frequently higher than those for the metal grades of the deposit. Therefore, borehole spacing chosen based on the grade variations cannot adequately capture the geological contact variability. Consequently, models created using such boreholes cause high volumetric uncertainties in the actual and targeted ore extraction volumes, which, in turn, lead to high unplanned dilution and ore losses. In this paper, a method to design optimum ore/mining boundaries for lateritic metal deposits is presented. The proposed approach minimizes the dilution/ore losses and comprises two main steps. First, the uncertainty on the orebody boundary is represented using a set of stochastic realizations generated with a multiple-point statistics algorithm. Then, the optimal orebody boundary is determined using an optimization technique inspired by a model calibration method called Pilot Points. The pilot points represent synthetic elevation values and they are used to construct smooth mining boundaries using the multilevel B-Spline technique. The performance of a generated surface is evaluated using the expected sum of losses in each of the stochastic realizations. The Simulated Annealing algorithm is used to iteratively determine the pilot point values which minimize the expected losses. The results show a significant reduction in the dilution volume as compared to those obtained from the actual mining operation.
\end{abstract}

Y. Dagasan $(\varangle) \cdot$ O. Erten · E. Topal

Department of Mining and Metallurgical Engineering, Western Australian School of Mines Curtin University, 6430, Kalgoorlie, WA, Australia

E-mail: yasin.dagasan@postgrad.curtin.edu.au

P. Renard · J. Straubhaar

Centre for Hydrogeology and Geothermics, University of Neuchâtel, rue Emile-Argand 11, 2000 Neuchâtel, Switzerland 
Keywords Multiple-point statistics - Direct Sampling - Bauxite mining · Laterite Simulated Annealing · Optimization · Dig Limit

\section{Introduction}

Given a laterite-type bauxite deposit formed from tropically weathered maficultramafic complexes, the bauxite mineral exists in the soil horizons (Erten 2012). Therefore, the deposit can be mined easily by a front-end loader due to the free-flow characteristics of the loose soil. Being an underlying geological unit, ferricrete is very likely to dilute the bauxite ore during mining operations due to poorly defined geological interface between bauxite and ferricrete units. Although this dilution can partly be alleviated by the front-end loader operator, who subjectively discriminates the bauxite ore from the ferricrete based on the hardness and color differences of the geological units at the time of mining, it still cannot be avoided entirely.

Ferricrete dilution is the major cause of high silica content in the bauxite ore, as it is tremendously rich in silica-bearing minerals such as kaolinite and quartz (Morgan 1995). The contact topography between the bauxite and ferricrete units is rather undulating and cannot be modeled satisfactorily by using an economically viable drilling program, as the drill spacing is usually determined based on the continuity and variation in the aluminum grade (Singh 2007; Hartman and Mutmansky 2002). In other words, since the peaks and troughs cannot be sampled adequately, they cannot be inferred from the geostatistical estimates either (Philip and Watson 1986). This situation is also illustrated in Figure 1. Failing to model the contact surface accurately introduces a major uncertainty, which may then lead to the following: (1) inaccurate calculations of the ore volume/tonnage and the quantity of the caustic soda being consumed; and (2) subjective ore extraction strategies by the front-end loader operators.

There are several ways to reduce the uncertainty in the contact surface and its possible consequences. One of the easiest ones would be to conduct a dense drilling program to capture the peaks and troughs of the contact surface. However, this would dramatically increase the associated costs making the operation less profitable and even not feasible at all. Another way to reduce the uncertainty in the contact surface models is the use of geophysical methods to contribute to the orebody delineation (Campbell 1994; Fallon et al. 1997). Among the geophysical methods, ground penetrating radar (GPR) has been efficiently used to improve the delineation of ore/waste boundaries in lateritic ore bodies (Francke 2010, 2012b a) Francké and Nobes 2000

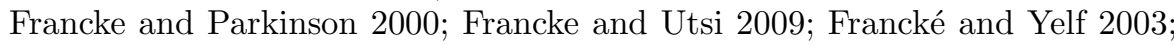
Barsottelli-Botelho and Luiz 2011; Dagasan et al. 2018). However, GPR surveys alone cannot replace the traditional drilling due to their lack of accuracy. They are most efficiently used as secondary information to complement the borehole data through geostatistical data integration techniques (Erten 2012). Applications of such data integration presented by Erten (2012); Erten et al. 


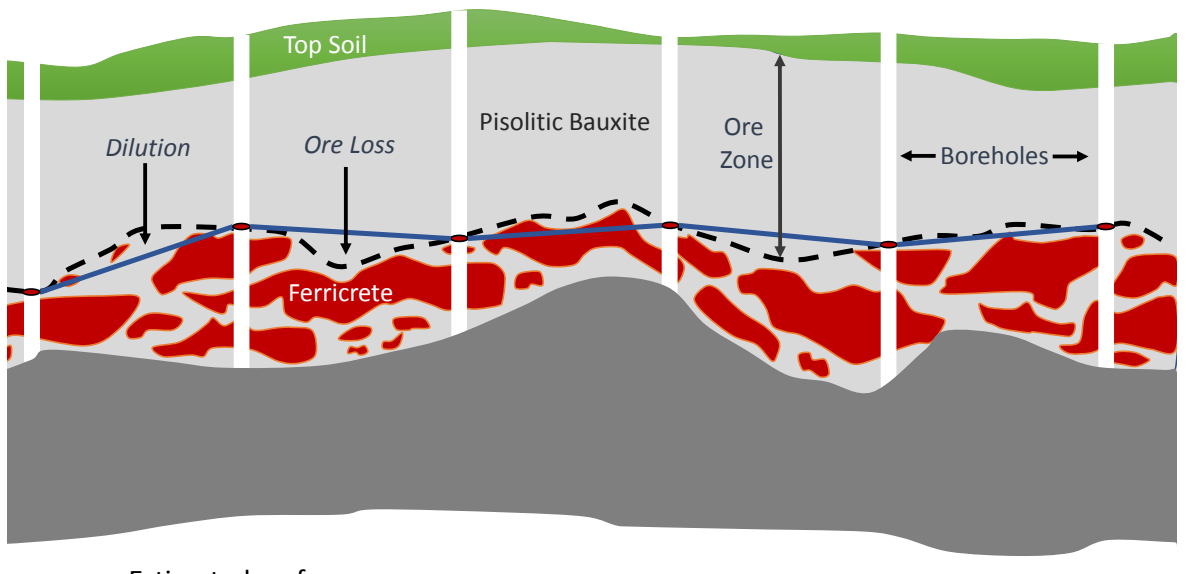

Estimated surface

- - - Actual surface

Fig. 1: The peaks and troughs of the actual ore/waste interface cannot be detected by an economically viable drilling spacing. This results in an inaccurate estimation of the ore/waste contact (after Erten 2012)

(2013, 2015) demonstrate the benefits of using the secondary information on the model precision. However, even though a better model representing the ore/waste contact surface is attained, the large spatial variations inherent to the ore/waste interface limits the mining equipment to track down a given contact surface accurately.

Due to large spatial variations and the uncertainties inherent to the geological contact, any excavation surface inevitably causes dilution and ore losses. Although this problem shows a similarity with the dig-limit problems in open-pit mining, which has been covered by several studies such as Norrena and Deutsch (2001, 2002); Richmond (2004); Richmond and Beasley (2004); Isaaks et al. (2014); Ruiseco et al. (2016); Ruiseco and Kumral (2017); Sari and Kumral (2018), the problem with lateritic deposits is rather specific due to the nature of free-digging mining method. Research on finding the optimum elevation values for a lateritic nickel mine has been carried out by McLennan et al. (2006), but the focus was to optimize the dilution and ore losses. The approach did not put a strong emphasis on the equipment selectivity due to low dilution/ore loss ratio and good equipment selectivity.

The aim of this research is to design optimum extraction boundaries for lateritic metal deposits based on the simulated ore/waste interface. The proposed approach can be used to generate mining boundaries minimizing the unplanned dilution and ore loss as well as increasing the mining equipment flexibility. It is inspired by a model calibration technique, which is frequently used in hydrogeology, called pilot points. In this technique, several pilot points are first placed in the area to be mined out. These pilot points represent synthetic elevation values and act as points controlling the shape of proposed 
extraction boundaries. The elevation values at the pilot points are iteratively modified in order to find a smooth excavation surface minimizing the possible dilution and ore losses. Multilevel B-spline method (MBS) (Lee et al. 1997) was used to create a smooth surface by interpolating the values at the pilot point locations with a predefined smoothness parameter. The losses associated with a decision surface are calculated using several hundreds of equiprobable realizations generated using the direct sampling (DS) (Mariethoz et al. 2010) multiple-point statistics algorithm. This makes the generated excavation surfaces account for the uncertainties in the ore/waste interface. The elevation values at the pilot point locations were iteratively optimized using the simulated annealing (SA) algorithm (Kirkpatrick et al. 1983), which uses the sum of the losses in all the realizations as the objective function. The pilot point values yielding minimum losses were then employed to construct the suggested extraction surface.

\section{Review of underlying methods}

The following subsections provide the required background information to comprehend these methods, which form the foundations of the methodology described in Section 3 .

\subsection{The Direct Sampling MPS Algorithm}

The direct sampling (DS) is a pixel-based MPS algorithm used to simulate a random function $Z(x)$ on a simulation grid (SG) (Mariethoz et al. 2010). It stochastically reproduces the spatial or temporal patterns in the simulation domain by integrating the datasets from analogue sites through training images (TI) Oriani et al. 2014, Pirot et al. 2014). A TI serves as a conceptual geological model and contains spatial structures that are thought to exist in the simulation area (Guardiano and Srivastava 1992). The DS uses the spatial patterns in the TI to stochastically simulate a random function $Z(x)$. The steps to perform the simulations are as follows:

1. Migrate any available conditioning data to the SG.

2. Visit a non-informed grid node at $x$ following a predefined random or regular path.

3. Determine $n$ number of closest informed nodes at $\left\{x_{1}, x_{2}, \ldots, x_{n}\right\}$.

4. Define the lag vectors $L=\left\{h_{1}, h_{2}, \ldots, h_{n}\right\}$, where $h_{i}=x_{i}-x$, to construct the data event $d_{n}(x, L)=\left\{Z\left(x+h_{1}\right), \ldots, Z\left(x+h_{n}\right)\right\}$.

5. Randomly scan the TI at $y$ locations and calculate the distance between $d_{n}(x, L)$ and $d_{n}(y, L)=\left\{Z\left(y+h_{1}\right), \ldots, Z\left(y+h_{n}\right)\right\}$ until it falls below a threshold $t$ or a maximum scan fraction $f$ is reached.

6. Take the pattern as the best match and paste the central node $Z(y)$ to the grid node at $x$ location.

7. Repeat the steps 2-6 until all the grid nodes are informed. 
The DS algorithm also makes it possible for multivariate simulations of $m$ variables, which are spatially dependent by an unknown function (Mariethoz et al. 2010). This is basically carried out by computing the distances between the joint data events $d_{n}(x)$ and $d_{n}(y)$ of $m$ variables in both the SG and the TI, respectively. In this research, the MPS simulations were carried out by calling the DS algorithm, which is coded in C, from R software (Team 2017). The version of the DS used is called DeeSse (Straubhaar 2016). Detailed information on the algorithm can be found in Mariethoz et al. (2010); Meerschman et al. (2013); Straubhaar (2016).

\subsection{Pilot Point Method (PPM)}

PPM is an inverse modeling technique that is commonly used to calibrate groundwater models (Jung 2008). It was first suggested by de Marsily et al. (1984) and later modified by several researchers Certes and de Marsily (1991); LaVenue et al. (1995); RamaRao et al. (1995); Oliver et al. (1996); Cooley (2000); Alcolea et al. (2006). The primary motivation of the PPM was to overcome the non-uniqueness and instability problems of the previous inverse techniques using a reduced parameter space. In this method, several calibration points are first chosen from the model domain where there are no conductivity measurements taken. These points are called pilot points and represent synthetic conductivity values to be iteratively calibrated by minimizing the squared errors between the actual and observed head values. At every step, the pilot point values are used to generate the conductivity field using a geostatistical interpolation technique with a particular prescribed spatial structure inferred from the measurements.

In this research, the PPM was tailored for a mining application. Rather than calibrating the conductivity field, the method was used to create optimum mining boundaries. The pilot points located within the modelling domain control the shape of the mining boundaries and were iterated to seek the pilot point values yielding minimised dilution and ore losses. The details of our proposed mining application are explained in the following sections.

\subsection{Multilevel B-Splines}

The MBS method was used to interpolate or approximate a scattered dataset (Lee et al. 1997). Given a scattered dataset $P=\left\{\left(x_{c}, y_{c}, z_{c}\right)\right\}$ on a $\Omega$ domain, the method uses $z_{c}$ values at $\left(x_{c}, y_{c}\right)$ locations to carry out the approximations. A function $f(x, y)$ approximating the values $z_{c}$ at $\left(x_{c}, y_{c}\right)$ locations were sought to interpolate the $Z$ field. To carry out this, the method utilizes a hierarchy of control lattices $\Phi_{0}, \Phi_{1}, \ldots, \Phi_{h}$ overlain the domain $\Omega$. Each of the control lattices $\Phi_{k}$ contains a different number of control points with varying spacing. The spacing between the control points of a $\Phi_{k}$ is always halved for the subsequent control lattice $\Phi_{k+1}$. Therefore, the $0^{t h}$ control lattice $\Phi_{0}$ becomes the 
coarsest and $\Phi_{h}$ as the finest. Approximation with the coarsest control lattice $\Phi_{0}$ comprises the first step of the MBS method yielding $f_{0}$ function. Being an initial smooth approximation, $f_{0}$ results in a deviation $\Delta^{1} z_{c}=z_{c}-f_{0}\left(x_{c}, y_{c}\right)$ for each point $\left(x_{c}, y_{c}, z_{c}\right)$. The algorithm proceeds by using the next control lattice $\Phi_{1}$ to generate a function $f_{1}$ which approximates the preceding deviation $P_{1}=\left\{\left(x_{c}, y_{c}, \Delta^{1} z_{c}\right)\right\}$. A better approximation with a less departure from the original data points $P$ would then be obtained by the sum of $f_{0}+f_{1}$. This would result in the deviation $\Delta^{2} z_{c}=z_{c}-f_{0}\left(x_{c}, y_{c}\right)-f_{1}\left(x_{c}, y_{c}\right)$. Therefore, the deviation for a level $k$ can be calculated as $\Delta^{k} z_{c}=z_{c}-\sum_{i=0}^{k-1} f_{i}\left(x_{c}, y_{c}\right)$. Since the origin of the approach creates a surface approximating the points $P$, the interpolation is achieved through a sufficiently small finest control lattice $\Phi_{h}$. The introduction of the adaptive control lattice hierarchy helps to achieve finer lattices with a reasonable memory requirement. More information regarding the theory can be found in Lee et al. (1997). The MBS method in this research is implemented using the MBA package created for the $\mathrm{R}$ statistics software (Finley and Banerjee 2010).

\subsection{Simulated Annealing (SA) Algorithm}

Simulated annealing (SA) is one of the stochastic optimization techniques used to solve global optimization problems (Kirkpatrick et al. 1983, Xiang et al. 2013). The method finds the global minimum of an objective function by mimicking the annealing process of a molten metal. The artificial temperatures used in the algorithm allows to regulate the cooling schedule and to introduce stochasticity. This stochasticity is basically used to avoid the solution from trapping inside a local minimum by changing the probability of acceptance throughout the cooling schedule.

Given an objective function $f(x)$ with the decision variables $x=\left(x_{1}, x_{2}, \ldots, x_{n}\right)$, the SA algorithm utilizes the following to attain a global minimum (Sun and Sun 2015):

1. Set a high initial temperature value $T_{0}$ and an initial solution $x^{0}$ to evaluate the objective function $E^{0}=f\left(x^{0}\right)$.

2. Propose a new candidate solution $x^{i+1}$ :

- Propose a candidate solution $x^{i+1}$ based on the current one $\left(x^{i}\right)$ through a predefined visiting distribution.

- Evaluate the energy difference $\Delta E=f\left(x^{i+1}\right)-f\left(x^{i}\right)$ to observe the change in the objective function for the candidate solution.

- Accept the iteration if the candidate solution reduces the objective function, $\Delta E<0$.

- If the new candidate yields a greater objective function value, accept or reject the solution based on a probability of acceptance criterion.

3. Repeat step 2 for $L$ number of iterations holding $T$ constant.

4. Reduce the temperature to $T_{n+1}$ based on a cooling function.

5. Repeat steps 2-4 until the convergence is achieved. 
In this research, Generalized Simulated Annealing (GSA) method (Tsallis and Stariolo 1996) was used to optimize the pilot point values. It makes use of the distorted Cauchy-Lorentz visiting distribution to seek for an optimum solution (Tsallis and Stariolo 1996). The GSA offers different options for the stopping criteria such as maximum running time, maximum function calls, maximum iteration number or a threshold value for the objective function. The implementation of the GSA was performed using the GenSA package of the $\mathrm{R}$ statistics software (Xiang et al. 2013). The default SA parameters of the package were set to solve complex optimization problems (Xiang et al. 2017). Therefore, these values were used to optimize the pilot point values in this research.

\section{Methodology}

The methodology of the proposed approach includes several steps to generate an optimum ore/waste boundary. First one of these is to create an ensemble of equiprobable realizations representing the uncertainty on the position of the ore/waste interface. This step is followed by locating some pilot points in the simulation grid and fitting a smooth surface to them. The elevation values of the pilot points are then iterated and updated using the SA to seek the combination of the pilot point values minimizing the total losses in each of the realizations. These steps are illustrated in Figure 2, More information about the steps is given in the following subsections.

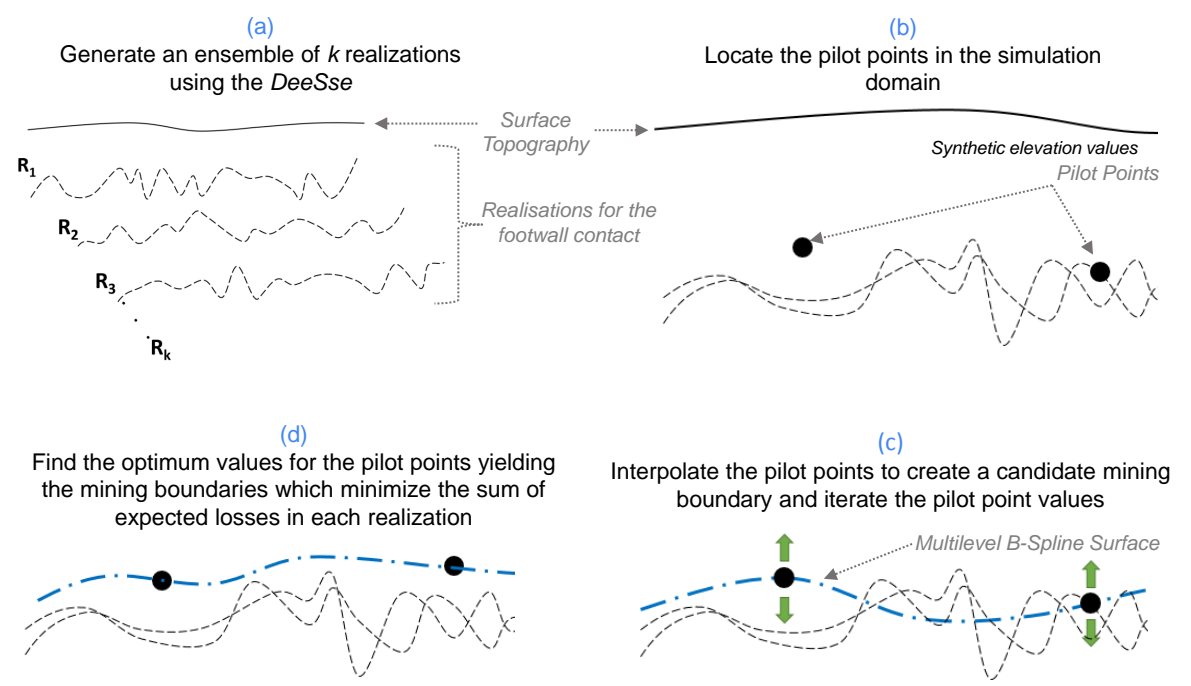

Fig. 2: The main steps of the proposed methodology. See text for detailed explanations. 


\subsection{Simulations of the bauxite/ferricrete contact}

The proposed methodology requires an ensemble of $k$ conditional realizations $R=\left\{R_{j} \mid j=1,2, \ldots, k\right\}$ representing the ore/waste interface generated as a first step. In order to perform the simulations, the borehole elevations of the geological contact were used as the conditioning data. Available GPR survey of the area, on the other hand, was used as the secondary information to guide the simulations. Creating such realizations rather than a single estimation plays an important role in integrating the uncertainty in the designed excavation surface.

The required simulations in this research were obtained using the DS MPS algorithm due to the benefits it provides in modeling the ore/waste boundaries of lateritic metal deposits. For instance, it utilizes a TI as a structural model, rather than a variogram. Therefore, knowledge on the spatial structures can be inferred from the previously mined-out areas through the TI concept. Since the mined-out topographies represent a complete picture of the geological variations inherent in the contact, they can provide rich structural information. In classical geostatistics, such information is derived from the sparse borehole data, which only offer a partial knowledge of the ground truth. An additional benefit of using a TI is that the resulting modeling framework is rather nonexpert friendly as variogram modeling is not needed. Furthermore, the DS allows performing multivariate simulations by utilizing the multiple point dependence between multiple images. If geophysical data are available, as in our case, this can be incorporated easily in the modeling.

Although the use of MPS offers some benefits, the requirement of a TI to perform the simulations might sometimes limit its application. For instance, after the extraction of a bauxite deposit, a mined-out surface is exposed and this can be used as a TI through a topographic survey. However, such a survey data may not always be readily available. In such cases, the contact simulations can be performed using standard geostatistical simulation techniques as well. The DS MPS algorithm has been used in this research since a mined-out floor survey (TI) was already available.

\subsection{Locating pilot points}

Once a set of realizations for the footwall topography are generated, the next step involves locating several pilot points $\theta=\left\{\theta\left(x_{l}\right) \mid l=1,2, \ldots, m\right\}$ in the mining area. These pilot points function as synthetic elevation values, which are used to create an optimum ore/mining boundary through interpolation.

The process required to set-up the pilot points can be explained in four steps, as illustrated in Figure 3. The first one of these is to create a grid to store their values and locations. The resolution of this grid can be chosen to be the same as the SG. Once this is done, the next step comprises locating the pilot points based on a predefined spacing. In order to better observe the effects of the chosen spacing on the results in this study, pilot points were regularly 
spaced. That is, if the spacing is chosen as five grid nodes, the pilot points are located at every $5^{\text {th }}$ node of the pilot points grid. After this step, the initial values of the pilot points (synthetic elevation values) need to be assigned. This can either be performed by drawing numbers from a random number generator or using the simulations. The random values for the pilot points can be generated within a defined upper and lower boundary. Such boundaries can be determined using the maximum elevation value of the surface topography and the minimum elevation value of the contact realizations. Getting the initial values from the simulations can simply be achieved by copying the elevation values from the nodes of a realization which are co-located with the pilot points. The final pilot point values, on the other hand, are decided by the SA algorithm iteratively and lead to minimized dilution and ore losses. If the boundaries of the grid do not have at least one pilot point, additional pilot points are also placed at the boundaries. These additional points are required to make the interpolation cover the whole modeling domain. For example, when locating the pilot points in Figure 3, no points were placed in the right, left and bottom boundaries initially. Therefore, three random locations in each boundary were chosen to place an additional three pilot points.

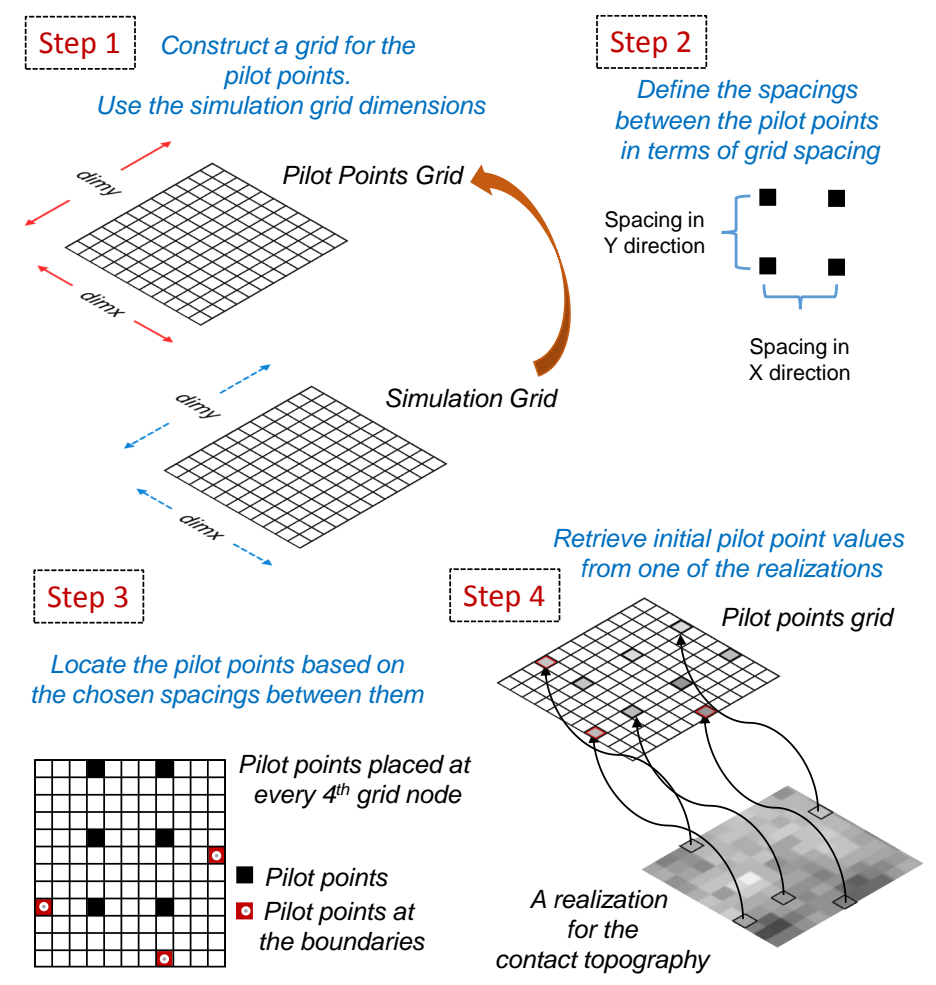

Fig. 3: Steps followed to locate the pilot points and assign their initial values in the mining area 
It should be noted that the spacing chosen between the pilot points affect the smoothness of the created mining boundaries as well as the dilution/ore loss amounts. If the spacing between the pilot points is small, the resulting surface becomes more detailed. Therefore, it is advised to determine this number based on the equipment flexibility as well. A surface created using dense pilot points would yield an uneven surface which would increase the time and fuel consumption required to perform the excavation task.

\subsection{Smooth excavation surface design}

Multilevel B-spline is used as an interpolation technique to construct the smooth excavation surface. The construction of the surface is mainly accomplished by interpolating the $Z$ field at each grid node of the mine area using a number $\theta$ of pilot points. The degree of fluctuations that the resulting surface exhibits is primarily influenced by two factors. The first one is the number of $h$ levels used in the MBS interpolation. As this number increases, the fluctuations of the constructed surface also increases due to better approximations made in the finer levels. The second factor is related to the spacing between the pilot points. Small spacing values between pilot points result in an increased number of pilot points. This would then lead to greater variations in the interpolated surface. We consider the fluctuations of the resulting surface as an essential factor for the equipment flexibility. Being able to adjust this allows one to integrate the equipment flexibility in the designed excavation surface.

\subsection{Loss calculation-Objective Function}

The objective of the optimization is to find the $\theta=\left\{\theta\left(x_{l}\right) \mid l=1,2, \ldots, m\right\}$ pilot point values, which lead to the decision surface $S^{d}(\theta)$ that minimizes the sum of expected economical losses in an ensemble of $k$ realizations:

$$
\min _{\theta} \sum_{j=1}^{k} L_{j}(\theta)
$$

where $L_{j}(\theta)$ is the loss incurred in the realization $R_{j}$ due to the decision surface $S^{d}(\theta)$. It can be calculated as follows:

$$
L_{j}(\theta)=p_{j}^{\max }-p_{j}^{a c t}(\theta)
$$

where $p_{j}^{\max }$ represents the maximum profit that can potentially be made if all the ore between the surface topography and the ore/waste contact of the $j^{\text {th }}$ realization were extracted. It can be calculated by multiplying the unit profit $P$ by the extracted volume:

$$
p_{j}^{\max }(\theta)=P \sum_{i=1}^{n} T_{i, j}^{\max }(\theta) \cdot A
$$


where $T_{i, j}^{\max }$ represents the maximum bauxite thickness at the $i^{\text {th }}$ grid node of the $j^{t h}$ realization (see Figure 4,$A$ represents the area of a grid cell and $n$

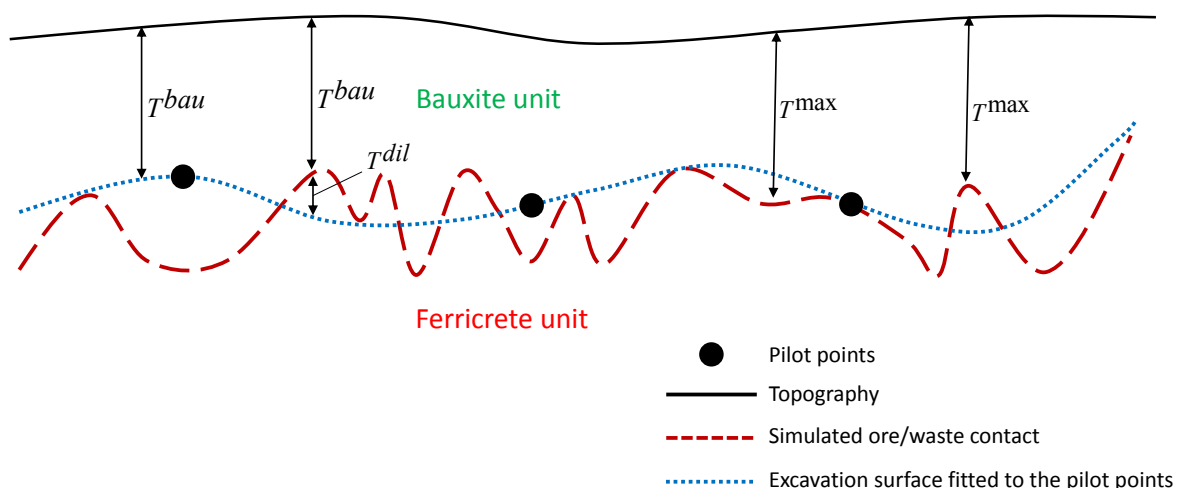

Fig. 4: Thicknesses used to calculate the losses due to an excavation surface

represents the number of informed grid nodes in the simulation area. $T_{i, j}^{\max }$ can simply be calculated by subtracting the elevation of the footwall topography realisations from those of the surface topography $Z_{i}^{\text {topo }}$ :

$$
T_{i, j}^{\max }=Z_{i}^{\text {topo }}-R_{i, j}
$$

$p_{j}^{a c t}(\theta)$, on the other hand, represents the actual profit that can be made out of $R_{j}$ if the mining is carried out following the boundaries defined by the decision surface $S^{d}(\theta)$. Its calculation is performed by subtracting the cost of dilution from the profit made out of extracting the ore at each grid node:

$$
p_{j}^{a c t}(\theta)=P \sum_{i=1}^{n} T_{i, j}^{b a u}(\theta) \cdot A-C \sum_{i=1}^{n} T_{i, j}^{d i l}(\theta) \cdot A
$$

where $T_{i, j}^{b a u}$ represents the mined bauxite (ore) thickness using the decision surface $S^{d}(\theta), T_{i, j}^{d i l}$ represents the ferricrete (waste) thickness overlying the decision surface and $C$ represents the unit cost of dilution. These thicknesses can be calculated as follows:

$$
\begin{aligned}
T_{i, j}^{\text {bau }}(\theta) & =Z_{i}^{\text {topo }}-\max \left(R_{i, j}, \min \left(Z_{i}^{\text {topo }}, S_{i}^{d}(\theta)\right)\right) \\
T_{i, j}^{\text {dil }}(\theta) & =R_{i, j}-\min \left(R_{i, j}, \min \left(Z_{i}^{\text {topo }}, S_{i}^{d}(\theta)\right)\right)
\end{aligned}
$$

To sum up, the objective function used for the optimization was evaluated based on the expected losses incurred due to a decision surface $S_{d}(\theta)$. Its calculation was performed in four steps: (1) generation of an ensemble of realizations (only for once), (2) generating a set of pilot points, (3) fitting an MBS surface to the pilot points and (4) evaluating the loss due to the constructed smooth surface in each of the stochastic realizations. 
3.5 Determination of optimum values at the pilot points

The pilot point values yielding an excavation surface that minimizes the expected loss were determined by the optimization framework of the SA algorithm. Steps of the optimization framework to design the optimal mining boundaries can be seen in Figure 5 .

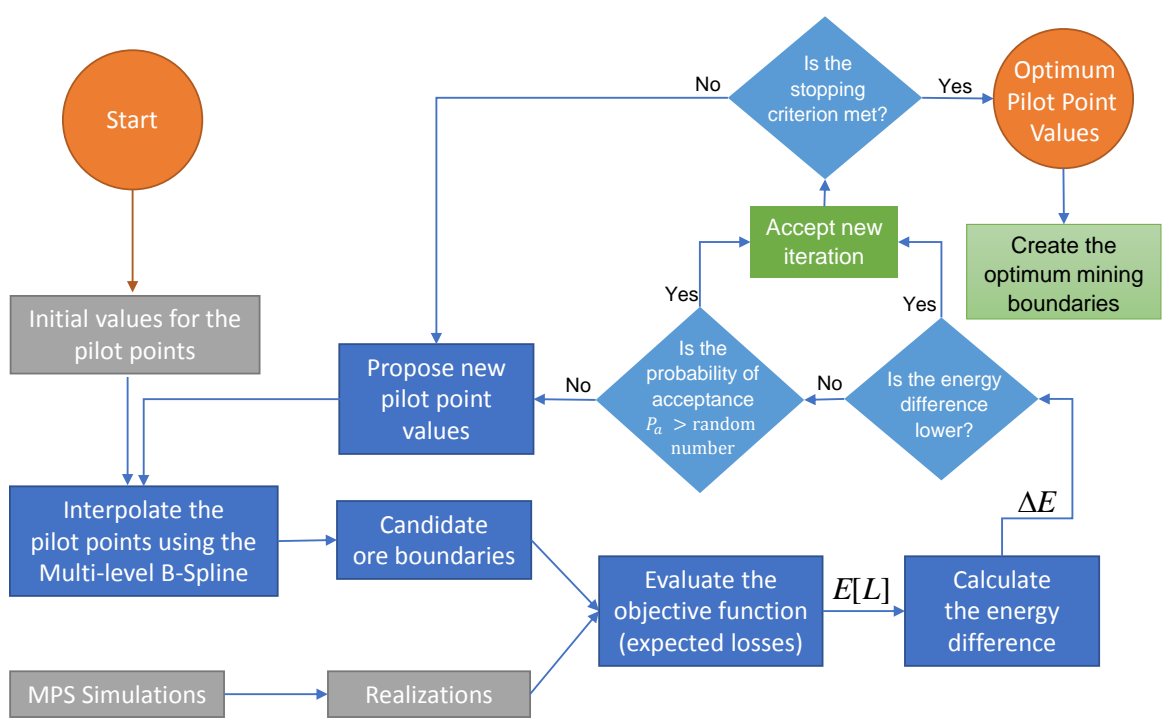

Fig. 5: Steps used to determine the pilot points yielding optimum mining boundaries

Given a set of initial $\theta$ pilot points (vector of decision variables), an MBS surface is first fitted to them, and the sum of losses in all the realizations is calculated. The SA algorithm then perturbs the pilot point values using the Cauchy-Lorentz visiting distribution to evaluate the performance of a new solution (losses caused by the updated pilot point values). A change in the pilot point values yielding an improvement in the objective function (reduction in the losses) is always accepted. On the other hand, any change in the pilot point values resulting in a worse solution (increase in the loss) can be accepted or rejected based on the probability calculated using the generalized Metropolis algorithm. The acceptance probability depends on the artificial temperature parameter of the SA. As the temperature set is high in the initial stages of the optimization process, the probability of accepting worse solutions is high as well. Therefore, the solution space is well explored in the beginning. As the iterations progress, the probability of accepting a worse solution goes down since the artificial temperature approaches to zero. After several thousands of iterations, the SA converges and finds the $\theta_{\text {opt }}$ pilot point values minimizing 
the losses. Once the optimum pilot point values are found, they are then used to design an optimum excavation surface through the MBS method.

\section{Results and Discussion}

The proposed approach was implemented to generate optimum mining boundaries for a laterite-type bauxite deposit. Being an initial step of the proposed methodology, simulations of the bauxite/ferricrete interface were first performed. In order to achieve this, the elevation variable of the interface was used as the attribute to be simulated. Due to the existence both of boreholes and ground penetrating radar data (GPR), the simulations were performed in the form of bivariate simulations. This was carried out by utilizing the borehole data as the primary variable to condition the simulations and GPR data, which is exhaustively sampled throughout the simulation domain, as the secondary information to guide the simulations.

Both the borehole and the GPR data contain the elevation variable of the bauxite/ferricrete interface. The borehole elevations were obtained by observing the elevation values at which the lithology changes from bauxite to ferricrete. The GPR elevations, on the other hand, were obtained indirectly from the original raw GPR measurements. In the first place, the raw GPR data were acquired in two-way travel time. Therefore, it initially allowed the determination of the depth from the surface to the bauxite/ferricrete interface. After subtracting the depths to the interface from the surface elevations, the GPR elevations for the bauxite/ferricrete were obtained. These elevations were used as the secondary variable to guide the simulations. The conditioning data used in the simulations are shown in Figure 6.

A bivariate TI was then constructed to infer the multiple-point dependence between the borehole and the GPR data. Its variables comprise an exposed mined-out surface of a previously extracted mining area and an extensive GPR survey conducted before mining. The variables of the constructed TI can be seen in Figure 7 .

The grid used to store the TI dataset consists of 180 nodes in easting (X) and 400 nodes in northing (Y) directions. On the other hand, the SG is comprised of 97 and 214 nodes in both easting and northing directions, respectively. The single grid size is defined as $2.38 \times 2.38 \mathrm{~m}$ for both the TI and the SG grids. Since the original data for the GPR and the mined-out floor surface were in the form of point data, they were migrated to the TI grid node locations. This was performed through the conditional sequential Gaussian simulation (sGs) technique so as to preserve the original statistical properties as well as avoiding any smoothing effect. Using the constructed TI, the DS was used to generate an ensemble of 200 realizations. The average of the resulting simulations can be seen in Figure 8 .

The pilot points were placed in the simulation domain based on a defined grid spacing between them. In order to analyze the effect of the spacing on the losses and the fluctuations of the decision surface, pilot points spaced 8 , 


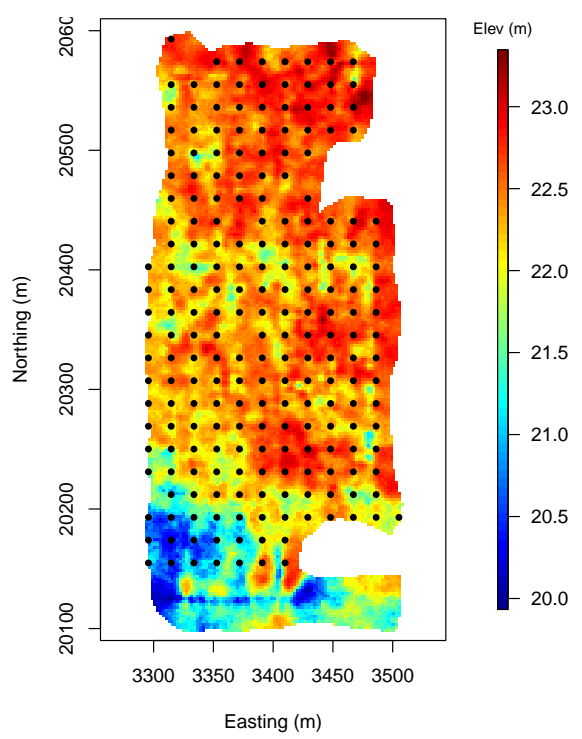

Fig. 6: Conditioning data used in the simulations. Black dots represent the borehole data locations (primary variable) and the underlying image represents the GPR data (secondary variable)

16 and 24 number of grids were tested. The defined spacings yielded 251, 60 and 26 pilot points, respectively. Plan views of the pilot point locations in the mining area can be seen in Figure 9

In addition to the spacings between the pilot points, the number of $h$ levels used in the MBS method also affects the smoothness of the decision surface. This parameter was chosen as 10 in this study based on visually inspecting the smoothness of the resulting surface. Although our choice in this research was mainly due to the visual inspection, we suggest that a suitable value of this parameter be determined in the future to yield a design surface mimicking the front-end loader equipment selectivity.

The loss calculations require some unit costs and profits be defined. These include the profit $P$ of mining a unit volume of bauxite ore and the cost $C$ incurring in the case of a unit volume of dilution. Since the grade distribution does not show a significant variability throughout the deposit, we simply assume that the $\mathrm{Al}_{2} \mathrm{O}_{3} \%$ grades overlying the ore/waste interface are the same everywhere. A similar assumption was also made for the $\mathrm{SiO}_{2} \%$ grades within the ferricrete unit. Therefore, given that the dilution is approximately 60 times costlier than ore loss in the mining of such deposits (Erten 2012), we simply assumed that a unit loss occurring due to dilution basically costs $\$ 60$. We also assumed that the profit made when one unit of ore is mined is $\$ 1$. It should be noted that these prices are hypothetical and might not reflect the reality.

Optimization process begins with assigning an initial set of values for the pilot points to be optimized. These values can either be randomly chosen or 
(a)

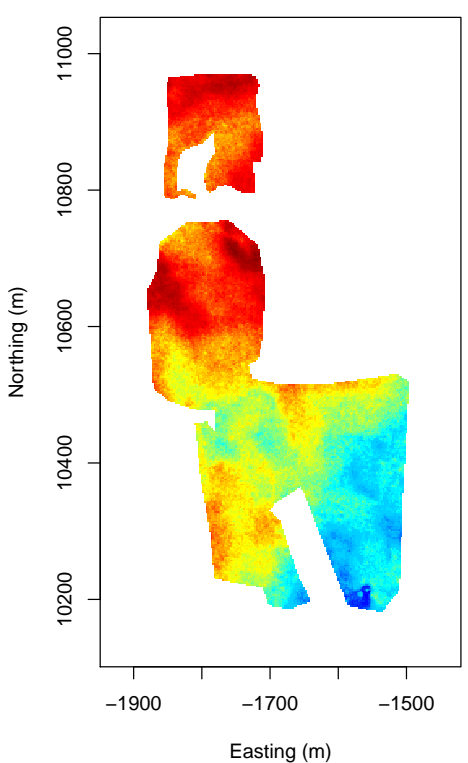

(b)

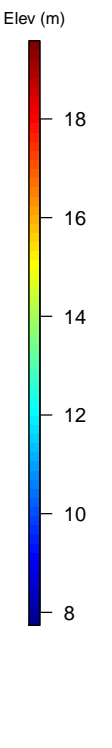

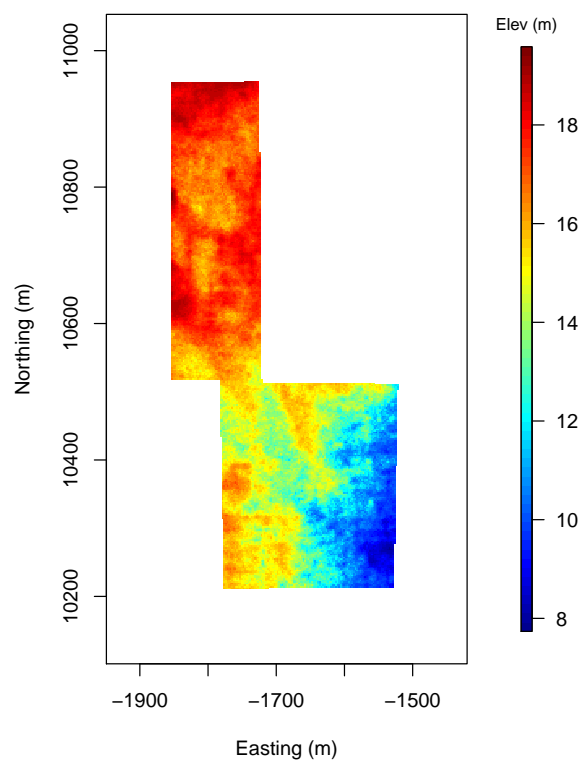

Fig. 7: The constructed bivariate TI: (a) extraction surface of a previously mined out area and (b) extensive GPR survey carried out prior to the excavation of the mining area

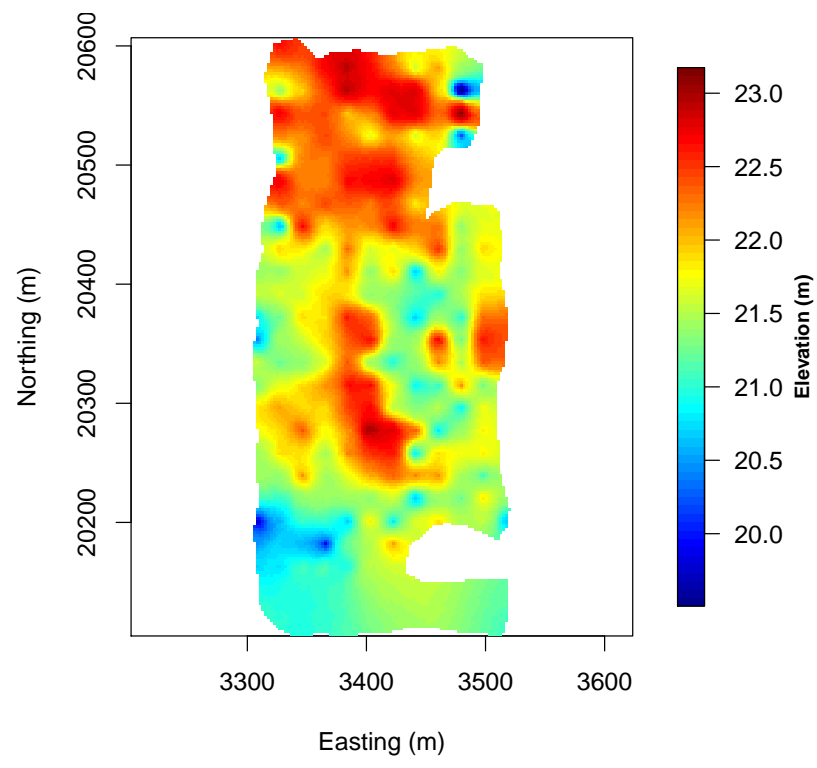

Fig. 8: Average of 200 realizations representing the bauxite/ferricrete interface 

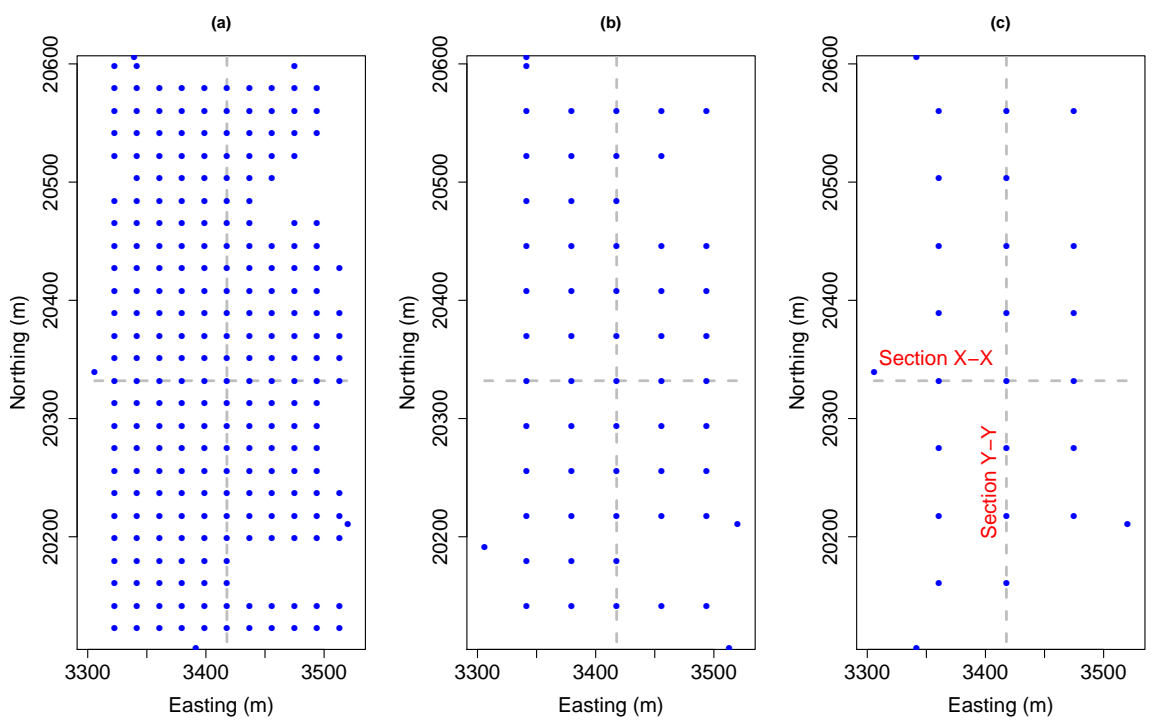

Fig. 9: Locations of the pilot points in the mine area. Blue dots represent the pilot points located at every (a) 8th grid node, (b) 16th grid node and (c) 24th grid node. The dashed lines represent the coordinates where the cross-sections were taken as presented in Figures 10 and 11

pre-specified before the optimization. In our case, the values were taken from the elevation values corresponding to the average of 200 realizations at the pilot point locations. We also defined a lower and an upper boundary in which the optimum values of the pilot points are sought. These boundaries function as the constraints of the optimization. The lower boundary was calculated based on the minimum elevation value of the bauxite/ferricrete realizations. Maximum elevation constraint, on the other hand, was the maximum elevation value of the topography. We defined the maximum iteration number of the SA as 50,000 and the temperature as 5,000. An objective function call during the optimization process leads to the loss calculation for 200 images, which were of size $97 \times 214$, to calculate the losses in each of the realizations. Having ran the SA using the defined setup, it converged and yielded the optimum pilot point values. The resulting cross-sections of the deposit for a different number of pilot points are shown in Figures 10 and 11 . Plan views of the generated smooth surfaces are shown in Figure 12 .

The cross-sections demonstrate that the optimum surfaces constructed lie above most of the realizations. This is mainly due to the introduction of a higher dilution cost compared to that of ore loss. The proposed approach automatically avoids generating a surface that causes dilution, as it leads to greater losses in the objective function. Note that the position of the decision surface may seem to be high above the simulations in certain cases, but this can be since we are only looking at a section while there are fluctuations in the 


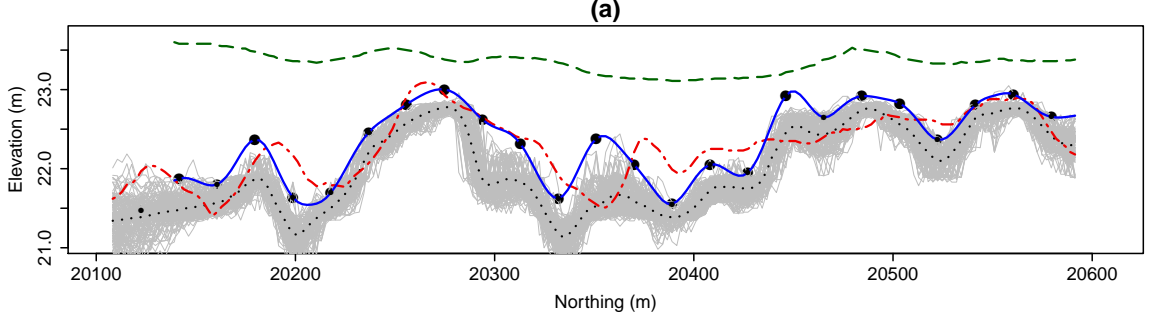

(b)

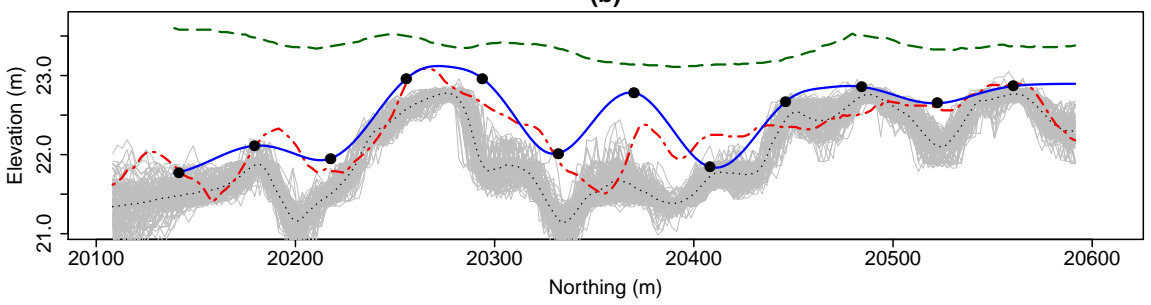

(c)

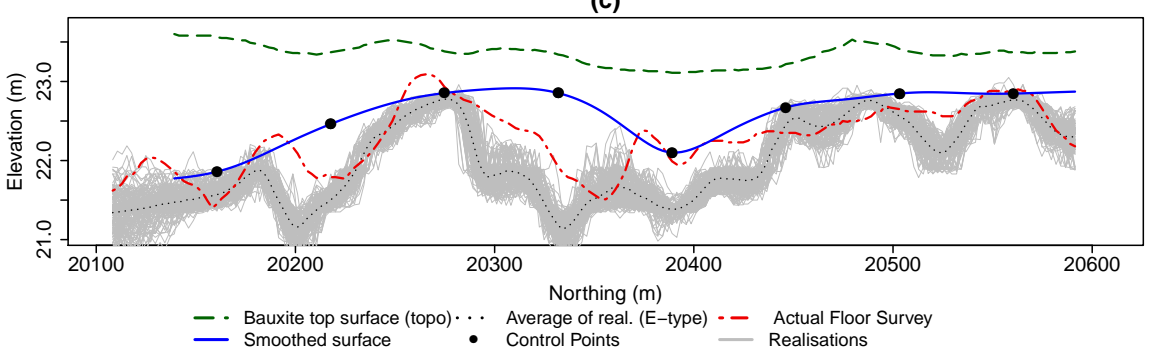

Fig. 10: Y-Y cross-sections of the optimum surfaces found by using (a) 251 pilot points, (b) 60 pilot points and (c) 26 pilot points

perpendicular direction that the decision surface needs to consider to remain optimal.

The use of a different number of pilot points has two main consequences. The first one is about the fluctuations seen in the decision surface generated. When the number of pilot points used increases, the decision surface exhibits more fluctuations. Similarly, the use of sparser pilot points yields decision surfaces that exhibit less fluctuations, as can be seen in Figure 12 . The second consequence is that the calculated losses decrease when the number of pilot points increases as shown in Figure 13. This indicates that there is a tradeoff between the fluctuations and the resulting losses. More pilot points allow defining a design surface that will be rougher and more difficult to excavate but will produce higher revenue.

Following the collection of the borehole and GPR data, the area was mined out by the front-end loader operator utilizing the hardness difference between the ore/waste to track the actual geological interface. The surface exposed was mapped through a topographic survey, and the collected survey points were then used to create the complete image of the mined-out surface. Point 
(a)

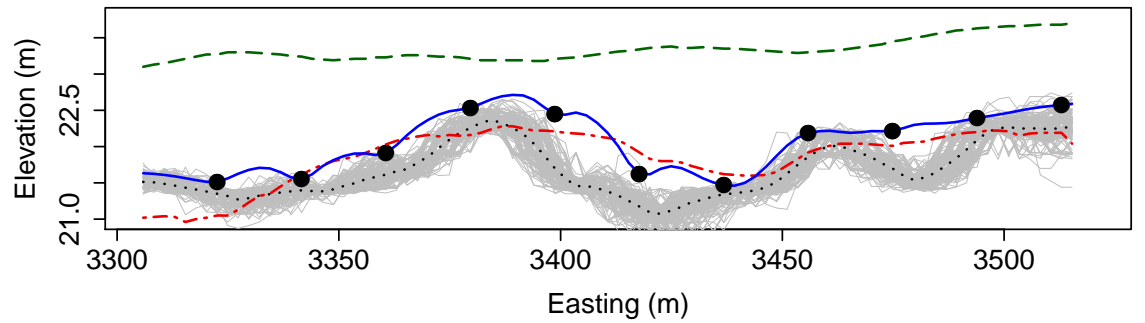

(b)

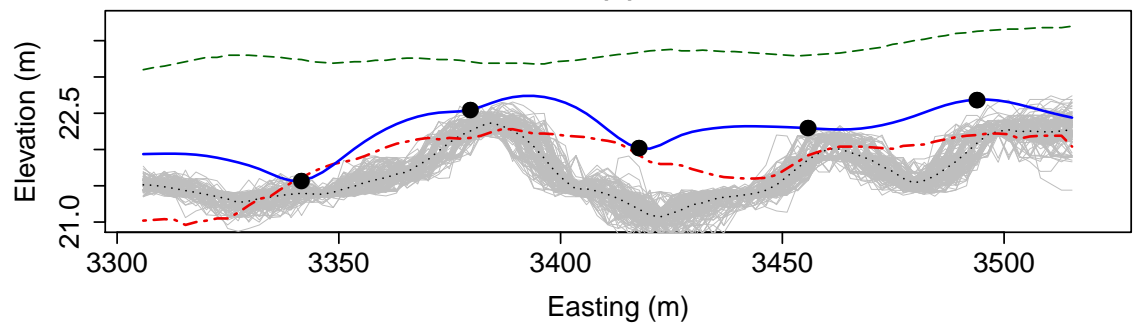

(c)

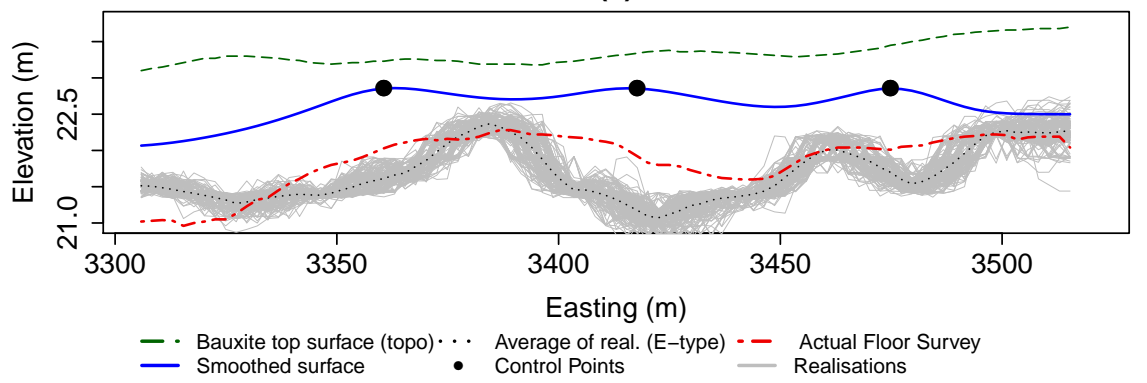

Fig. 11: X-X cross-sections of the optimum surfaces found by using (a) 251 pilot points, (b) 60 pilot points and (c) 26 pilot points

to grid data conversion has been achieved by the conditional sGs, as in the construction of the TI. The main idea was again to prevent any smoothing effect.

In order to make a comparison, the expected volumes for the bauxite reserve, mined portion of the reserve, dilution and ore losses were calculated using the three optimized boundaries. The expected reserve volume was calculated by taking the average of the volume between the surface topography and 200 contact realizations. For the mined reserve calculations, the bauxite volume overlying the optimized surfaces in 200 realizations were averaged. If the proposed surfaces were below a realization at a grid node, the elevation differences were multiplied by the area to calculate the dilution volume. The sum of all the dilution at each grid node yielded the total dilution amount for a realization. Similarly, if the optimized surfaces were above a realization, they 

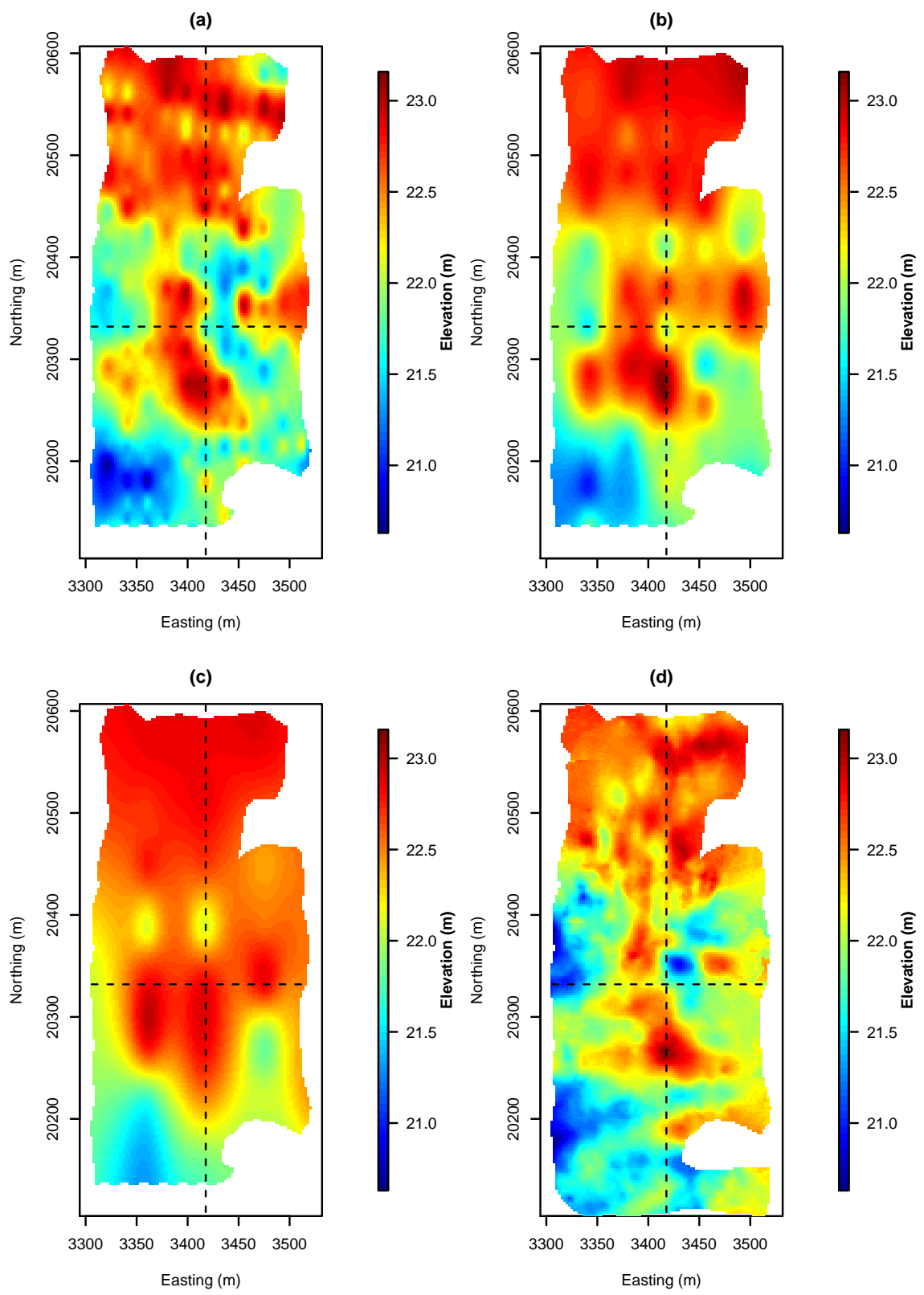

Fig. 12: Plan view of the excavation surface designed using (a) 251 pilot points, (b) 60 pilot points, (c) 26 pilot points and (d) the actual mined-out surface. The dashed lines show the sections where the cross-sections in Figures 10 and 11 were constructed. 
were considered to cause an ore loss and the associated volumes were calculated for each of the realizations. The dilution and ore losses calculated for 200 realizations were then averaged to find the expected dilution and ore losses for a given decision surface. In addition, the results of these optimized surfaces were also compared with the mined out surface using the same calculation logic. The summary of the volume calculations given in Table 1 demonstrates the benefit of the proposed method. Concerning the volume calculations, the bauxite mined using 251 pilot points comprises $77 \%$ of the expected bauxite reserve. This is very similar to the amount of bauxite mined by the operator, which was $76 \%$ of the deposit. However, although both of the surfaces result in obtaining the similar amount of bauxite deposit, the dilution amount resulted using 251 pilot point surface was $0.076 \%$ of the total mined volume and significantly lower than the dilution amount of mined out surface, which was $2.7 \%$. The percentages described are also illustrated in Figure 14 in terms of barplots.

Table 1: Statistics of the proposed and mined out surfaces

\begin{tabular}{lllll}
\hline Expected Stats & 251 Pilot Points & 60 Pilot Points & 26 Pilot Points & Mined Out \\
\hline Reserve Volume $\left(\mathrm{m}^{3}\right)$ & 130,448 & 130,448 & 130,448 & 130,448 \\
Mined Reserve $\left(\mathrm{m}^{3}\right)$ & 100,506 & 86,938 & 75,324 & 99,316 \\
Ore Loss $\left(\mathrm{m}^{3}\right)$ & 29,942 & 43,510 & 55,124 & 31,131 \\
Ferricrete Dilution $\left(\mathrm{m}^{3}\right)$ & 76 & 86 & 113 & 2791 \\
Economical Losses & $\$ 34,502$ & $\$ 48,713$ & $\$ 61,946$ & $\$ 159,104$ \\
\hline
\end{tabular}

\section{Summary and conclusions}

In this paper, we presented a new grade control technique to minimize the risk of operational dilution and ore losses in lateritic metal deposits. Although the development was performed on a lateritic metal deposit, the method can be applied to any stratified deposit to create an ore/waste boundary with a certain degree of smoothness. The proposed approach benefits from a parameter calibration technique called "pilot points" to create a design surface with multi-level B-spline method. The optimized pilot point values are iteratively obtained within the simulated annealing algorithm to create a new ore/waste boundary minimizing the risk of dilution and ore losses. Possible losses of a constructed surface are calculated using several scenarios of the ore/waste boundaries generated by the multiple-point statistical simulations. We have implemented the proposed approach on a lateritic bauxite deposit and compared the resulting losses with the ones calculated using the actual mining operation.

The major advantage of the proposed method is the reduction in the economical losses. Implementation of the method on bauxite has demonstrated much less losses compared to the actual mining operation that took place. It 
(a)

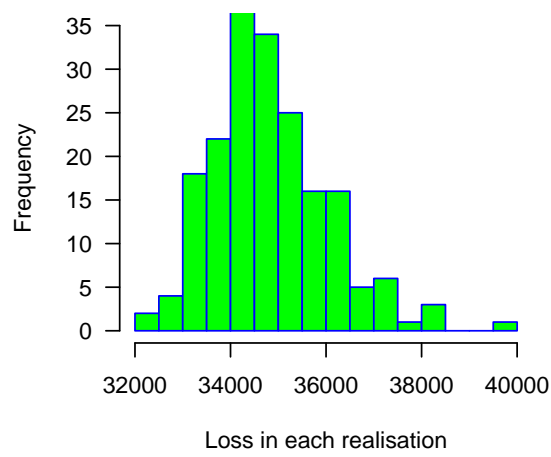

(c)

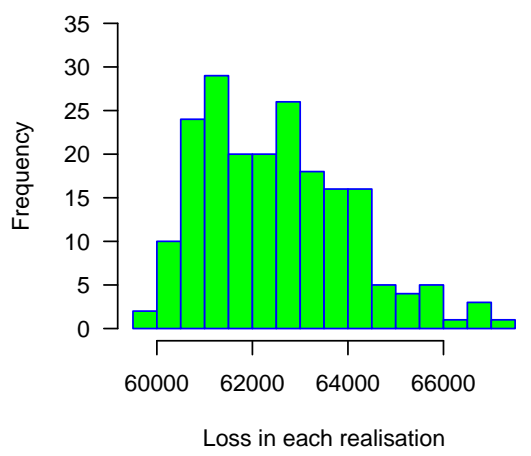

(b)

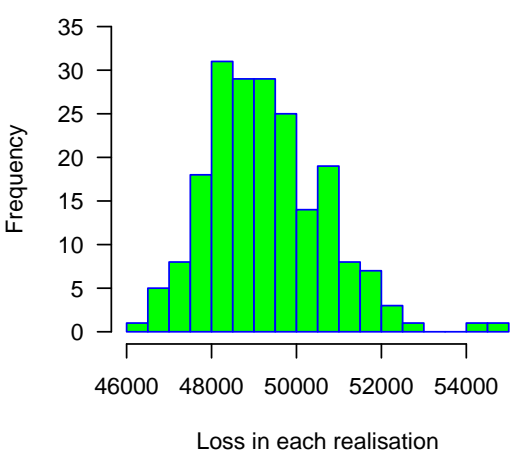

(d)

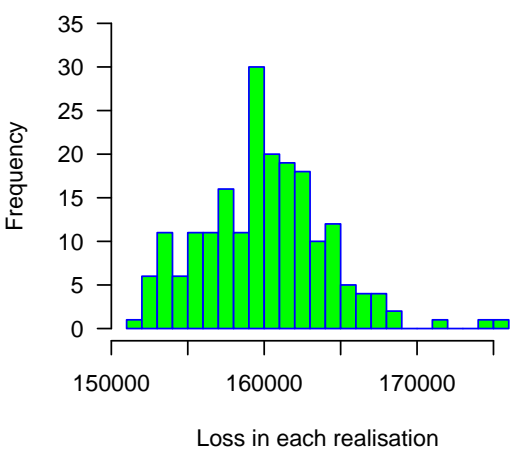

Fig. 13: Histograms of the losses calculated using the (a) 251 pilot points, (b) 60 pilot points and (c) 26 pilot points and (d) the actual mined out surface

was also observed that the losses resulting from our proposed approach are affected by the spacing between the pilot points. Densely spaced pilot points give smaller losses but increase the fluctuations in the resulting surface. Another benefit of the proposed approach comprises the integration of the uncertainties in the ore/waste contact. The losses of a decision surface are calculated using the equiprobable realizations representing the ore/waste interface. Therefore, the uncertainty in the ore/waste boundary is accounted for by the design surface. Although the realizations were generated using multiple-point statistics, the methodology could also work well with standard geostatistical simulations, such as Turning Bands. One should, however, be cautious of the quality of the simulations used as it significantly affects the designed surface. High variability in the ore/waste contact simulations, for instance, tends to result in a design surface deviating away from the average of the realizations due to the high 
(a)

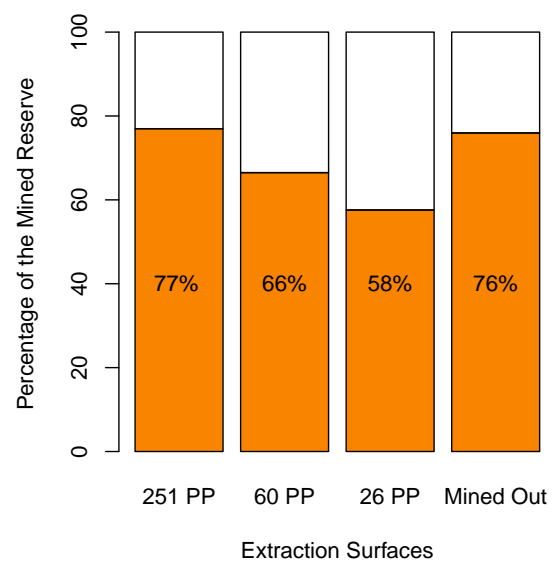

(b)

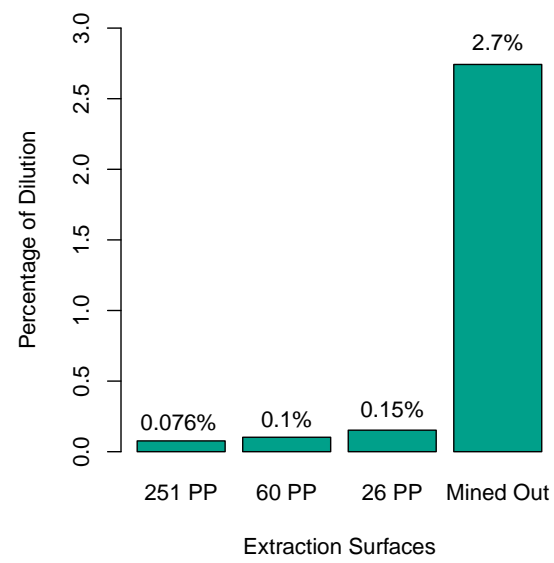

Fig. 14: Barplots representing (a) the mined bauxite ore percentage of the expected reserve and (b) dilution percentages of the total mined volumes

penalty associated with the dilution. This can lead to the underestimation of the mineable reserve volume.

The last benefit is about the adjustable smoothness of the generated surface. The number of $h$ levels of the multilevel B-spline method allows constructing surfaces with a varying degree of smoothness. This can help designing surfaces which are capable of reflecting the mining equipment selectivity. Although $h$ parameter of the multilevel B-spline fundamentally controls the smoothness of the surface, it needs to be calibrated in conjunction with the pilot point spacing used, as it also plays a crucial role on the fluctuations seen in the resulting surface.

The proposed approach reveals several points to be studied in the future as an improvement. The first one is the subjectivity introduced when placing the pilot points. The number and the locations of the pilot points are chosen based on personal preference in this study. Therefore, automatic determination of the number and the location of the pilot points as in Jiménez et al. (2016) may eliminate the subjectivity introduced. The second point that can be improved is related to the degree of smoothness that the decision surface exhibits. Since there is a trade-off between the losses and the degree of smoothness of the decision surface, the optimum degree of smoothness yielding minimum losses needs to be specified. This can be achieved by establishing a relationship between the surface smoothness and the mining equipment-related losses. Once such relationship is formulated as a function of the fluctuations of a given surface, this can then be used in the objective function as an additional term to calculate the total losses. Lastly, although the computation time required to perform the optimization was reasonable (6-8 hours) using the $\mathrm{R}$ software, it can significantly be reduced by utilizing parallel computing and coding in $\mathrm{C}$ language. 
Instead of using the multilevel B-Spline, alternative interpolation techniques, such as kriging, can be used to generate the excavation surface. The benefit of kriging would be the possibility to adjust the smoothness of the surface with the range parameter of the variogram model. In addition, it could be possible to infer this range from previously excavated surfaces. Therefore, the equipment flexibility can automatically be integrated into the designed surface with the prior knowledge from the mined-out areas. The implementation of multilevel B-splines in this research was due to its high-speed computation (Saveliev et al. 2005). Future research could investigate the use of kriging for the interpolation and explore its possible advantages.

Due to the fairly continuous nature of $\mathrm{Al}_{2} \mathrm{O}_{3} \%$ and $\mathrm{SiO}_{2} \%$ grades throughout the deposit and also for the sake of simplicity, the grades are considered constant in this study. Therefore, in order to squeeze more performance out of the approach and also to better reflect the reality, a block model of these attributes can also be constructed to calculate the losses. Use of such a model would then involve the loss calculations based on the partial or complete mining of a specific block.

Acknowledgements The authors would like to thank the editor and three anonymous reviewers for their valuable comments and suggestions. 


\section{References}

Alcolea, A., Carrera, J., and Medina, A. (2006). Pilot points method incorporating prior information for solving the groundwater flow inverse problem. Advances in Water Resources, 29(11):1678-1689.

Barsottelli-Botelho, M. and Luiz, J. (2011). Using gpr to detect bauxite horizons in laterite deposits of amazon basin, brazil. In 73rd EAGE Conference and Exhibition incorporating SPE EUROPEC 2011.

Campbell, G. (1994). Geophysical contributions to mine-development planning: A risk reduction approach. In 15th CMMI Congress, S. African Inst. Min. Metall., volume 3, pages 283-325.

Certes, C. and de Marsily, G. (1991). Application of the pilot point method to the identification of aquifer transmissivities. Advances in Water Resources, $14(5): 284-300$.

Cooley, R. L. (2000). An analysis of the pilot point methodology for automated calibration of an ensemble of conditionally simulated transmissivity fields. Water Resources Research, 36(4):1159-1163.

Dagasan, Y., Erten, O., and Topal, E. (2018). Accounting for a spatial trend in fine-scale ground-penetrating radar data: a comparative case study. The Journal of South African Institute of Mining and Metallurgy, 118(2):173184.

de Marsily, G., Lavedan, G., Boucher, M., and Fasanino, G. (1984). Interpretation of interference tests in a well field using geostatistical techniques to fit the permeability distribution in a reservoir model. Geostatistics for natural resources characterization, Part, 2:831-849.

Erten, O. (2012). Profiling and mining control to mitigate dilution effect from sio2 at the base of a bauxite deposit.

Erten, O., Kizil, M. S., Topal, E., and McAndrew, L. (2013). Spatial prediction of lateral variability of a laterite-type bauxite horizon using ancillary ground-penetrating radar data. Natural resources research, 22(3):207-227.

Erten, O., McAndrew, L., Kizil, M. S., and Topal, E. (2015). Incorporating fine-scale ground-penetrating radar data into the mapping of lateral variability of a laterite-type bauxite horizon. Mining Technology, 124(1):1-15.

Fallon, G., Fullagar, P., and Sheard, S. (1997). Application of geophysics in metalliferous mines. Australian Journal of Earth Sciences, 44(4):391-409.

Finley, A. and Banerjee, S. (2010). Mba: multilevel b-spline approximation. $R$ package version 0.0-7, URL http://CRAN. R-project. org/package $=M B A$.

Francke, J. (2010). Applications of gpr in mineral resource evaluations. In Ground Penetrating Radar (GPR), 2010 13th International Conference on, pages $1-5$. IEEE.

Francke, J. (2012a). A review of selected ground penetrating radar applications to mineral resource evaluations. Journal of Applied Geophysics, 81:29-37.

Francke, J. (2012b). The role of ground penetrating radar in bauxite resource evaluations. In Ground Penetrating Radar (GPR), 2012 14th International Conference on, pages 459-463. IEEE. 
Francke, J. and Parkinson, G. (2000). The new role of geophysics in nickel laterite exploitation and development. In Mining Millennium/PDAC 2000 Conference Proceedings, Toronto.

Francke, J. and Utsi, V. (2009). Advances in long-range gpr systems and their applications to mineral exploration, geotechnical and static correction problems. first break, 27(7).

Francké, J. C. and Nobes, D. C. (2000). Preliminary evaluation of gpr for nickel laterite exploration. In Eighth International Conference on Ground Penetrating Radar, volume 4084, pages 7-13. International Society for Optics and Photonics.

Francké, J. C. and Yelf, R. (2003). Applications of gpr for surface mining. In Advanced Ground Penetrating Radar, 2003. Proceedings of the 2nd International Workshop on, pages 115-119. IEEE.

Guardiano, F. and Srivastava, R. (1992). Borrowing complex geometries from training images: The extended normal equations algorithm. Stanford Center for Reservoir Forecasting Report, Stanford University.

Hartman, H. L. and Mutmansky, J. M. (2002). Introductory mining engineering. John Wiley \& Sons.

Isaaks, E., Treloar, I., and Elenbaas, T. (2014). Optimum dig lines for open pit grade control. In 9th International Mining Geology Conference, Adelaide, South Australia.

Jiménez, S., Mariethoz, G., Brauchler, R., and Bayer, P. (2016). Smart pilot points using reversible-jump markov-chain monte carlo. Water Resources Research, 52(5):3966-3983.

Jung, Y. (2008). Evolutionary algorithm based pilot point methods for subsurface characterization. PhD thesis, North Carolina State University.

Kirkpatrick, S., Gelatt, C. D., and Vecchi, M. P. (1983). Optimization by simulated annealing. science, 220(4598):671-680.

LaVenue, A. M., RamaRao, B. S., De Marsily, G., and Marietta, M. G. (1995). Pilot point methodology for automated calibration of an ensemble of conditionally simulated transmissivity fields: 2. application. Water Resources Research, 31(3):495-516.

Lee, S., Wolberg, G., and Shin, S. Y. (1997). Scattered data interpolation with multilevel b-splines. IEEE transactions on visualization and computer graphics, 3(3):228-244.

Mariethoz, G., Renard, P., and Straubhaar, J. (2010). The direct sampling method to perform multiple-point geostatistical simulations. Water Resources Research, 46(11).

McLennan, J., Ortiz, J., and Deutsch, C. (2006). Geostatistical simulation of optimum mining elevations for nickel laterite deposits. CIM Magazine, 1(6).

Meerschman, E., Pirot, G., Mariethoz, G., Straubhaar, J., Van Meirvenne, M., and Renard, P. (2013). A practical guide to performing multiple-point statistical simulations with the direct sampling algorithm. Computers 8 Geosciences, 52:307-324.

Morgan, C. (1995). Geology of the spheres at weipa. Trav. Com. Int. Etude Bauxites, Alumine Alum.(Yugoslavia), 22(24):61-74. 
Norrena, K. and Deutsch, C. (2001). Determination of dig limits subject to geostatistical, economic, and equipment constraints. In 2001 SME Annual Conference and Exhibition, pages 133-148.

Norrena, K. and Deutsch, C. (2002). Optimal determination of dig limits for improved grade control. In APCOM 2002: 30 th International Symposium on the Application of Computers and Operations Research in the Mineral Industry, pages 329-339.

Oliver, D. S., He, N., and Reynolds, A. C. (1996). Conditioning permeability fields to pressure data. In ECMOR $V$-5th European Conference on the Mathematics of Oil Recovery.

Oriani, F., Straubhaar, J., Renard, P., and Mariethoz, G. (2014). Simulation of rainfall time series from different climatic regions using the direct sampling technique. Hydrology and Earth System Sciences, 18(8):3015.

Philip, G. and Watson, D. (1986). Matheronian geostatisticsquo vadis? Mathematical Geology, 18(1):93-117.

Pirot, G., Straubhaar, J., and Renard, P. (2014). Simulation of braided river elevation model time series with multiple-point statistics. Geomorphology, 214:148-156.

RamaRao, B. S., LaVenue, A. M., De Marsily, G., and Marietta, M. G. (1995). Pilot point methodology for automated calibration of an ensemble of conditionally simulated transmissivity fields: 1 . theory and computational experiments. Water Resources Research, 31(3):475-493.

Richmond, A. (2004). Integrating multiple simulations and mining dilution in open pit optimisation algorithms. In Orebody Modelling and Strategic Mine Planning Conference.

Richmond, A. and Beasley, J. (2004). Financially efficient dig-line delineation incorporating equipment constraints and grade uncertainty. International Journal of Surface Mining, 18(2):99-121.

Ruiseco, J. R. and Kumral, M. (2017). A practical approach to mine equipment sizing in relation to dig-limit optimization in complex orebodies: multirock type, multi-process, and multi-metal case. Natural Resources Research, 26(1):23-35.

Ruiseco, J. R., Williams, J., and Kumral, M. (2016). Optimizing ore-waste dig-limits as part of operational mine planning through genetic algorithms. Natural Resources Research, 25(4):473-485.

Sari, Y. A. and Kumral, M. (2018). Dig-limits optimization through mixedinteger linear programming in open-pit mines. Journal of the Operational Research Society, 69(2):171-182.

Saveliev, A. A., Romanov, A. V., and Mukharamova, S. S. (2005). Automated mapping using multilevel b-splines. Applied GIS, 1(2):17-01.

Singh, N. (2007). Ground penetrating radar (gpr) in mineral base profiling and orebody optimization. In 6th International Heavy Minerals Conference, pages $185-194$.

Straubhaar, J. (2016). Deesse users guide. The Centre for Hydrogeology and Geothermics (CHYN), University of Neuchâtel. 
Sun, N.-Z. and Sun, A. (2015). Model Calibration and Parameter Estimation: For Environmental and Water Resource Systems. Springer.

Team, R. C. (2017). R: A language and environment for statistical computing. $\mathrm{r}$ foundation for statistical computing, vienna, austria. 2016.

Tsallis, C. and Stariolo, D. A. (1996). Generalized simulated annealing. Physica A: Statistical Mechanics and its Applications, 233(1-2):395-406.

Xiang, Y., Gubian, S., and Martin, F. (2017). Generalized simulated annealing. In Computational Optimization in Engineering-Paradigms and Applications. InTech.

Xiang, Y., Gubian, S., Suomela, B., and Hoeng, J. (2013). Generalized simulated annealing for global optimization: The gensa package. $R$ Journal, $5(1)$. 